\title{
Efficacy of intralipid administration to improve in vitro fertilization outcomes: A systematic review and meta-analysis
}

\author{
E Jung Han, Hye Nam Lee, Min Kyoung Kim, Sang Woo Lyu, Woo Sik Lee \\ Department of Obstetrics and Gynecology, Fertility Center of CHA Gangnam Medical Center, CHA University School of Medicine, Seoul, Korea
}

We performed a systematic review and meta-analysis to evaluate whether intralipid administration improved the outcomes of in vitro fertilization. Online databases (PubMed, Cochrane Library, Medline, and Embase) were searched until March 2020. Only randomized controlled trials (RCTs) that assessed the role of intralipid administration during in vitro fertilization were considered. We analyzed the rates of clinical pregnancy and live birth as primary outcomes. Secondary outcomes included the rates of chemical pregnancy, ongoing pregnancy, and missed abortion. We reviewed and assessed the eligibility of 180 studies. Five RCTs including 840 patients (3 RCTs: women with repeated implantation failure, 1 RCT: women with recurrent spontaneous abortion, 1 RCT: women who had experienced implantation failure more than once) met the selection criteria. When compared with the control group, intralipid administration significantly improved the clinical pregnancy rate (risk ratio [RR], 1.48; 95\% confidence interval [Cl], 1.23-1.79), ongoing pregnancy rate (RR, 1.82; 95\% Cl, 1.31-2.53), and live birth rate (RR, $1.85 ; 95 \% \mathrm{Cl}, 1.44-2.38)$. However, intralipid administration had no beneficial effect on the miscarriage rate (RR, $0.75 ; 95 \% \mathrm{Cl}, 0.48-1.17)$. A funnel plot analysis revealed no publication bias. Our findings suggest that intralipid administration may benefit women undergoing in vitro fertilization, especially those who have experienced repeated implantation failure or recurrent spontaneous abortion. However, larger, well-designed studies are needed to confirm these findings.

Keywords: In vitro fertilization; Infertility; Intralipid; Recurrent pregnancy loss; Repeated implantation failure

\section{Introduction}

Although in vitro fertilization (IVF) has come a long way, the success rate of IVF is still less than $40 \%$ [1]. Furthermore, approximately $10 \%$ of women who receive IVF with intracytoplasmic sperm injection experience repeated implantation failure (RIF) [2]. RIF is general-

Received: December 1, 2020 · Revised: March 9, 2021 · Accepted: April 6, 2021 Corresponding author: Sang Woo Lyu

Department of Obstetrics and Gynecology, Fertility Center of CHA Gangnam Medical Center, CHA University School of Medicine, 566 Nonhyeon-ro, Gangnam-gu, Seoul 06135, Korea

Tel: +82-2-3468-3000 Fax: +82-2-3468-2610 E-mail: dung5038@cha.ac.kr

* This research was supported by the Technology Innovation Program (or Industrial Strategic Technology Development Program, Grant No. 20003838) funded by the Ministry of Trade, Industry \& Energy (MI, Korea).

This is an Open Access article distributed under the terms of the Creative Commons Attribution Non-Commercial License (http://creativecommons.org/licenses/by-nc/4.0/) which permits unrestricted non-commercial use, distribution, and reproduction in any medium, provided the original work is properly cited. ly defined as three cycles of IVF that are unsuccessful even though 1-2 good-quality embryos are transferred in each cycle [3]. Impaired endometrial receptivity has been suggested as a major cause of RIF, and immune abnormalities reduce endometrial receptivity and consequently prevent implantation. Immune abnormalities have also been reported as the cause of recurrent spontaneous abortion (RSA) [4]. Therefore, many immunotherapies have been explored to improve endometrial receptivity and increase the pregnancy rate. Immunotherapy methods suggested for immune dysfunction include leukocyte immunization, intravenous immunoglobulin (IVIG), low-molecular-weight heparin, and intralipid [5,6].

Intralipid, which refers to a lipid emulsion comprising soybean oil, is an example of immunotherapy. Because intralipid is a source of fat, it has traditionally been used as a nutritional supplement for patients unable to eat orally. In addition to its nutritional role as an energy source, intralipid has biological functions, including immune function [7]. Although the immunological mechanism of intralipid is not 
fully understood, several studies have reported that its active component, soybean oil, inhibited the cytotoxic activity of natural killer (NK) cells $[8,9]$. Increased NK cell cytotoxicity has been associated with RSA and RIF $[10,11]$. In this context, many studies have explored the use of intralipid for women with/without RIF or RSA undergoing IVF [12-16]. However, the results of these studies have proven inconsistent and controversial. Therefore, the effectiveness of intralipid administration in infertile women undergoing IVF has not been conclusively established.

In view of the conflicting results of prior studies, we performed a systematic review and meta-analysis to evaluate the effect of intralipid administration on infertile women during IVF.

\section{Methods}

We followed the guidelines of the Cochrane Handbook for Systematic Reviews and preferred reporting items for systematic reviews and meta-analyses (PRISMA) checklist protocol. This study protocol was registered with PROSPERO (CRD42020201739).

\section{Eligibility criteria}

Only randomized controlled trials (RCTs) evaluating whether administration of intralipid plays a beneficial role in women undergoing IVF were considered. We included both published RCTs and unpublished RCTs and searched abstracts presented at major infertility conferences to identify any unpublished trials. Non-randomized studies were excluded from the current meta-analysis due to the high risk of bias. As the crossover design is invalid, these trials were also excluded. The target population was infertile women who had undergone IVF. We measured the rates of clinical pregnancy (CPR) and live birth (LBR) per randomized woman as the primary outcomes. Clinical pregnancy was determined based on the presence of a gestational sac and detectable fetal heartbeat. Live birth was defined as delivery of a live neonate after 24 weeks of gestational age. Secondary outcomes included the rates of ongoing pregnancy (defined when the pregnancy reached $\geq 12$ weeks of gestation) and missed abortion (defined as the intrauterine death of a fetus occurring before 20 weeks of gestational age) per randomized woman. We also assessed adverse events, including adverse reactions to intralipid administration and congenital anomalies.

\section{Search methodology for literature identification}

We searched online databases including PubMed, Medline, Embase, and the Cochrane Library for all relevant papers through March 2020. The following Medical Subject Headings (MeSH) and text terms were used to retrieve all relevant literature: "intralipid" and ("in vitro fertility" or "IVF" or "assisted reproductive techniques" or "ART" or "repeated implantation failure" or "RIF" or "recurrent pregnancy loss" or "RPL" or "recurrent miscarriage" or "recurrent spontaneous abortion" or "RSA"). There was no language restriction. Studies were independently identified by EJH and SWL.

\section{Study selection and data extraction}

Initially, two review authors (EJH and SWL) identified potentially relevant trials, and the retrieved titles and abstracts were then screened. We retrieved the full texts of all potentially eligible articles, and both authors (EJH and SWL) independently read through the full-text articles to determine whether they met the inclusion criteria and selected studies for inclusion in the review. Any disagreements regarding study eligibility were resolved by discussion or arbitration by a third author (WSL). The selection process was presented in a PRISMA flow chart.

\section{Assessment of risk of bias in the included studies}

Two review authors (EJH and SWL) independently evaluated the risk of bias in individual articles using the Cochrane Risk of Bias tool presented in the Cochrane Handbook for Systematic Reviews of Intervention (www.training.cochrane.org/ handbook). They evaluated the following seven sources of bias: (1) random sequence generation (selection bias); (2) allocation concealment (selection bias); (3) blinding of participants and personnel (performance bias); (4) blinding of outcome assessment (detection bias); (5) incomplete outcome data (attrition bias); (6) selective reporting (reporting bias); and (7) other sources of bias (other bias). We summarized the results of the risk of bias assessment for the included studies in graphs.

\section{Statistical analysis}

We conducted the meta-analysis using the RevMan 5.3 software package (Cochrane Collaboration, Oxford, UK). The risk ratios (RRs) with $95 \%$ confidence intervals ( $\mathrm{Cls}$ ) for binary data variables were calculated using the Mantel-Haenszel method. Using the $I^{2}$ statistic to assess the statistical heterogeneity across the included articles, we determined that statistical heterogeneity was absent when $l^{2}$ was $<50 \%$. In selecting the effect models, $I^{2}$ was used as the standard (fixed model: $l^{2}<50 \%$, random-effect model: $l^{2} \geq 50 \%$ ). We used a forest plot to graphically present the heterogeneity of the treatment effects. Publication bias was also estimated using funnel analysis and the Egger test. Forest plots were generated to present the results of the meta-analysis. When sufficient studies were available, we carried out further analyses within the following subgroups: (1) women without RIF or RSA versus women with RIF or RSA, and (2) women with previous implantation failure versus women with RSA. We also planned sensitivity analyses to evaluate whether our outcomes would have differed if (1) a random-effect model had been adopted, 
or (2) we had restricted the analysis to only published studies.

\section{Results}

\section{Study selection and characteristics}

In total, 180 articles were collected from electronic databases. Of these, 149 studies were considered ineligible as screening of the titles and abstracts revealed they did not meet the inclusion criteria. After reviewing the full texts of the remaining 31 studies, 26 studies were excluded for the following reasons: 10 studies were non-RCTs, nine studies were reviews, and seven studies reported no relevant comparisons or outcomes. Finally, five RCTs involving a total of 840 patients were included in the present meta-analysis [12-14,17,18]. The search results were presented in a PRISMA flow chart (Figure 1).

Three of the included trials were published as full articles [12-14], and two were published as conference abstracts $[17,18]$. Three studies evaluated the effects of intralipid administration on $\operatorname{RIF}[12,17,18]$, one study investigated the influence of intralipid administration on
RSA in patients with elevated NK cell levels (> 12\%) [13], and one study assessed the efficacy of intralipid for infertile women who experienced implantation failure more than once [14]. Most studies excluded women with an abnormal uterine cavity (i.e., endometrial polyp, submucosal myoma, or arcuate uterus). The method of intralipid administration varied among the included trials. In most studies, $20 \%$ intralipid was administered twice intravenously. For the first dose, intralipid was infused on the fourth to ninth day of controlled ovarian hyperstimulation [17], the day of ovum pick-up [13,14], or the day of embryo transfer [12]. The second dose of intralipid was administered on the day of embryo transfer [14], the day of the pregnancy test [12], or within 1 week of a positive pregnancy test [13,17]. All five included trials reported the CPR and LBR as outcomes. The chemical pregnancy rate was reported in two trials $[13,14]$, the ongoing pregnancy rate was reported in two trials $[13,14]$ and the miscarriage rate was reported in two trials $[12,13]$. Table 1 shows the characteristics of the five included studies.

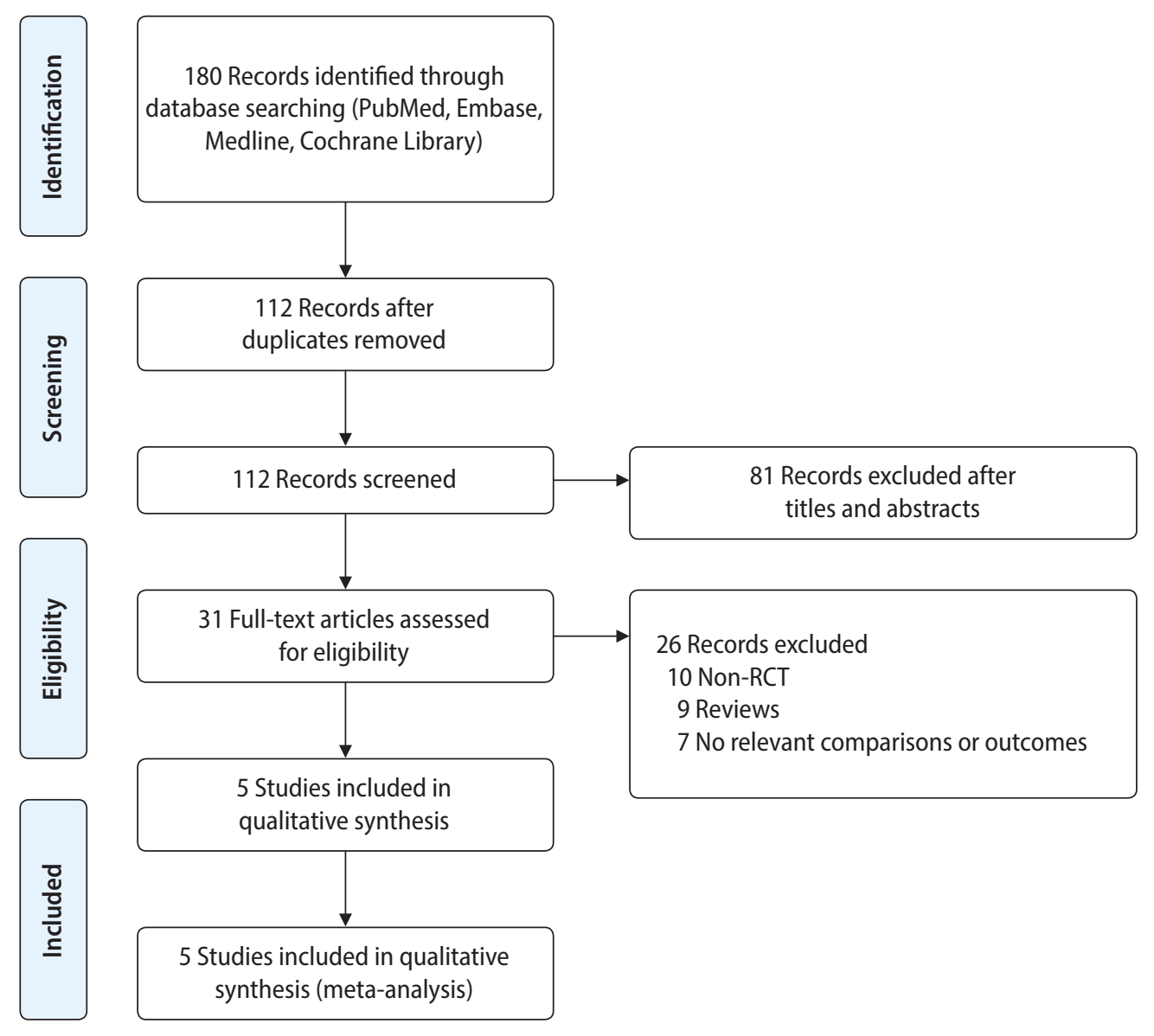

Figure 1. Preferred reporting items for systematic reviews and meta-analyses flow diagram of study selection. RCT, randomized controlled trial. 
Table 1. Characteristics of the included studies

\begin{tabular}{|c|c|c|c|c|c|c|}
\hline Study & Study design & $\begin{array}{c}\text { Participant } \\
\text { characteristics }\end{array}$ & $\begin{array}{l}\text { Sample size } \\
\text { (T/C) }\end{array}$ & Intervention & Control & Outcome \\
\hline $\begin{array}{l}\text { Al-Zebeidi et al. } \\
\text { (2020) [12] }\end{array}$ & $\begin{array}{l}\text { Randomized } \\
\text { controlled } \\
\text { study }\end{array}$ & $\begin{array}{l}\text { Unexplained re- } \\
\text { current implan- } \\
\text { tation failure } \\
\text { ( } \geq 3 \text { cycles) }\end{array}$ & $142(71 / 71)$ & $\begin{array}{l}\text { Intravenous infusion of intralipid ( } 100 \mathrm{~mL} \text { of } \\
20 \% \text { intralipid diluted in } 500 \mathrm{~mL} \text { of normal } \\
\text { saline) on the day of embryo transfer and a } \\
\text { second dose on the day of pregnancy test }\end{array}$ & No intervention & $\begin{array}{l}\text { Clinical pregnancy } \\
\text { rate, live birth rate, } \\
\text { miscarriage rate }\end{array}$ \\
\hline $\begin{array}{l}\text { Singh et al. } \\
\text { (2019) [14] }\end{array}$ & $\begin{array}{l}\text { Randomized } \\
\text { controlled } \\
\text { study }\end{array}$ & $\begin{array}{l}\text { Previous implan- } \\
\text { tation failure } \\
\text { ( } \geq 1 \text { cycle) }\end{array}$ & $102(52 / 50)$ & $\begin{array}{l}\text { Intravenous infusion of intralipid ( } 4 \mathrm{~mL} \text { of } \\
20 \% \text { intralipid diluted in } 250 \mathrm{~mL} \text { of normal } \\
\text { saline) on the day of oocyte retrieval (after } \\
\text { retrieval) and a second dose on the day of } \\
\text { embryo transfer, } 1 \text { hour prior to transfer }\end{array}$ & $\begin{array}{l}\text { Intravenous saline } \\
\text { injection }\end{array}$ & $\begin{array}{l}\text { Chemical pregnancy } \\
\text { rate, clinical preg- } \\
\text { nancy rate, implan- } \\
\text { tation rate, ongo- } \\
\text { ing pregnancy rate, } \\
\text { live birth rate }\end{array}$ \\
\hline $\begin{array}{l}\text { Gamaleldin et al. } \\
\text { (2018) [18] }\end{array}$ & $\begin{array}{l}\text { Randomized } \\
\text { controlled } \\
\text { study }\end{array}$ & $\begin{array}{l}\text { Unexplained re- } \\
\text { current implan- } \\
\text { tation }\end{array}$ & $97(48 / 49)$ & $\begin{array}{l}\text { Intravenous infusion of intralipid ( } 20 \% \text { ) start- } \\
\text { ing 6-7 days before embryo transfer and a } \\
\text { second dose in case of a positive pregnancy } \\
\text { test }\end{array}$ & $\begin{array}{l}\text { Intravenous saline } \\
\text { injection }\end{array}$ & $\begin{array}{l}\text { Clinical pregnancy } \\
\text { rate, live birth rate }\end{array}$ \\
\hline $\begin{array}{l}\text { Dakhly et al. } \\
\text { (2016) [13] }\end{array}$ & $\begin{array}{l}\text { Randomized } \\
\text { controlled } \\
\text { study }\end{array}$ & $\begin{array}{l}\text { Recurrent sponta- } \\
\text { neous abortion } \\
(\geq 3) \text { with ele- } \\
\text { vated NK cell } \\
\text { levels ( }>12 \%)\end{array}$ & $296(144 / 152)$ & $\begin{array}{l}\text { Intravenous infusion of intralipid ( } 2 \mathrm{~mL} \text { of } \\
20 \% \text { intralipid diluted in } 250 \mathrm{~mL} \text { of normal } \\
\text { saline) on the day of oocyte retrieval and re- } \\
\text { peated within } 1 \text { week of a positive pregnan- } \\
\text { cy test and every } 2 \text { weeks until the end of } \\
\text { the first trimester }\end{array}$ & $\begin{array}{l}\text { Intravenous saline } \\
\text { injection }\end{array}$ & $\begin{array}{l}\text { Chemical pregnancy } \\
\text { rate, clinical preg- } \\
\text { nancy rate, ongo- } \\
\text { ing pregnancy rate, } \\
\text { live birth rate, mis- } \\
\text { carriage rate }\end{array}$ \\
\hline $\begin{array}{c}\text { El-Khayat et al. } \\
\text { (2015) [17] }\end{array}$ & $\begin{array}{l}\text { Randomized } \\
\text { controlled } \\
\text { study }\end{array}$ & $\begin{array}{l}\text { Unexplained re- } \\
\text { current implan- } \\
\text { tation failure } \\
\text { (2-6 cycles) }\end{array}$ & $203(101 / 102)$ & $\begin{array}{l}\text { Intravenous infusion of intralipid ( } 20 \%) \text { be- } \\
\text { tween day } 4 \text { and } 9 \text { of ovarian stimulation } \\
\text { and a second dose when participants be- } \\
\text { came pregnant, within } 1 \text { week of the posi- } \\
\text { tive pregnancy test }\end{array}$ & $\begin{array}{l}\text { Intravenous saline } \\
\text { injection }\end{array}$ & $\begin{array}{l}\text { Clinical pregnancy } \\
\text { rate, implantation } \\
\text { rate, live birth rate }\end{array}$ \\
\hline
\end{tabular}

No data were presented about the NK cell level except by Dakhly et al. [13].

$\mathrm{T}$, trial group; $\mathrm{C}$, control group; NK, natural killer.

\section{Methodological quality of the included studies}

Most of the included trials had a relatively low to moderate risk of bias according to the guidelines of the Cochrane Collaboration (Supplementary Table 1). We present the outcomes of the risk of bias assessments for the included studies in figures (Supplementary Figures 1 and 2).

\section{Outcome measures}

\section{1) Clinical pregnancy rate}

All five included RCTs (840 patients) reported the CPR. All five RCTs showed that the CPR was higher in the intralipid group than in the placebo group, but the results were statistically significant in only two RCTs $[14,17]$. Pooling of the data showed a significant improvement in the CPR in the intralipid group when compared with the control group (RR, 1.48; 95\% Cl, 1.23-1.79; $p=0.13$ ). Heterogeneity was not found among the trials, as judged by the $I^{2}$ value $(45 \%)$. Thus, we selected a fixed-effect model (Figure 2A).

\section{2) Live birth rate}

All five included RCTs (840 patients) were eligible for inclusion in the meta-analysis of the LBR. In three of the five RCTs, it was con- firmed that intralipid significantly increased the LBR when compared to the placebo group $[13,14,17]$. The RR for the LBR was $1.85(95 \% \mathrm{Cl}$, 1.44-2.38) in favor of intralipid administration for infertile women undergoing IVF. Homoge-neity was found among the five RCTs according to the $I^{2}$ value (0\%). According to the result of $I^{2}$, we analyzed the data using a fixed-effect model (Figure 2B).

\section{3) Ongoing pregnancy rate}

Two trials (398 patients) assessed the ongoing pregnancy rate $[13,14]$. Both studies noted that the rate of ongoing pregnancy in the intralipid group was significantly higher than that in the placebo group. The results of the meta-analysis showed a higher ongoing pregnancy rate when intralipid was administered $(\mathrm{RR}, 1.82 ; 95 \% \mathrm{Cl}$, $1.31-2.53 ; p=0.38)$. When the $I^{2}$ statistic was calculated, no heterogeneity was identified $\left(I^{2}=0 \%\right)$. We performed the meta-analysis using a fixed-effect model because $I^{2}$ was $<50 \%$ (Figure $3 A$ ).

\section{4) Miscarriage rate}

The miscarriage rate was reported in two RCTs with 438 patients $[12,13]$. One of them showed that intralipid significantly decreased the miscarriage rate when compared to the control group [13]. Pool- 


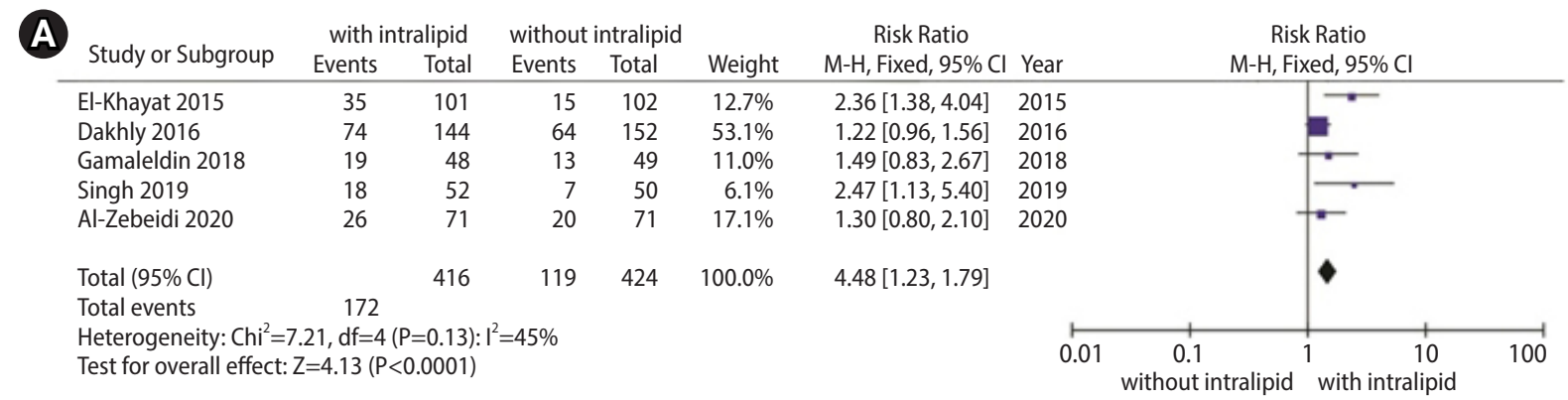

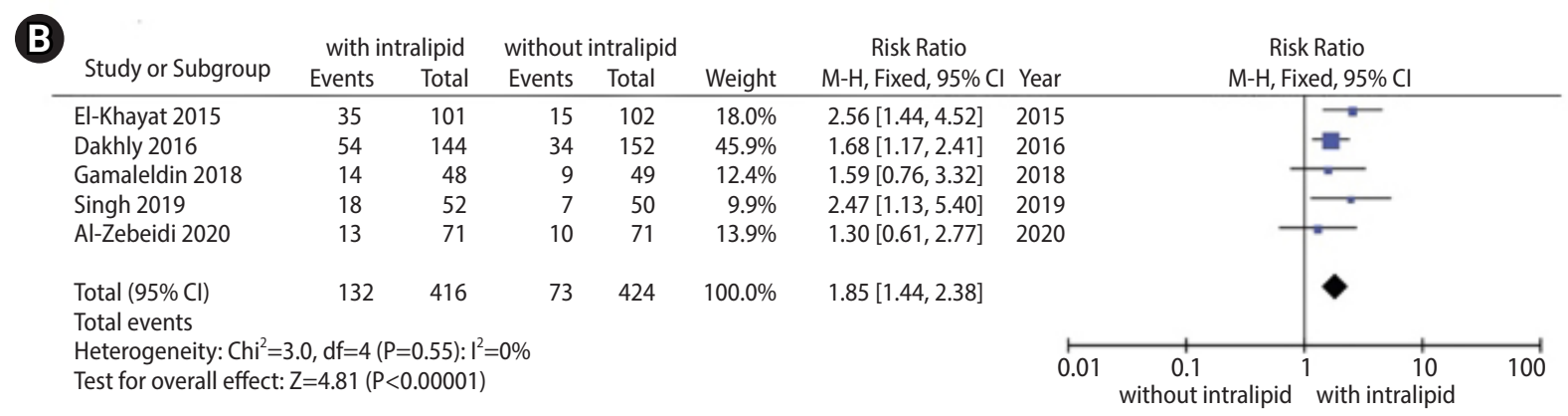

Figure 2. Meta-analysis of the clinical pregnancy rate (A) and live birth rate (B). $M-H$, Mantel-Haenszel; $\mathrm{Cl}$, confidence interval.

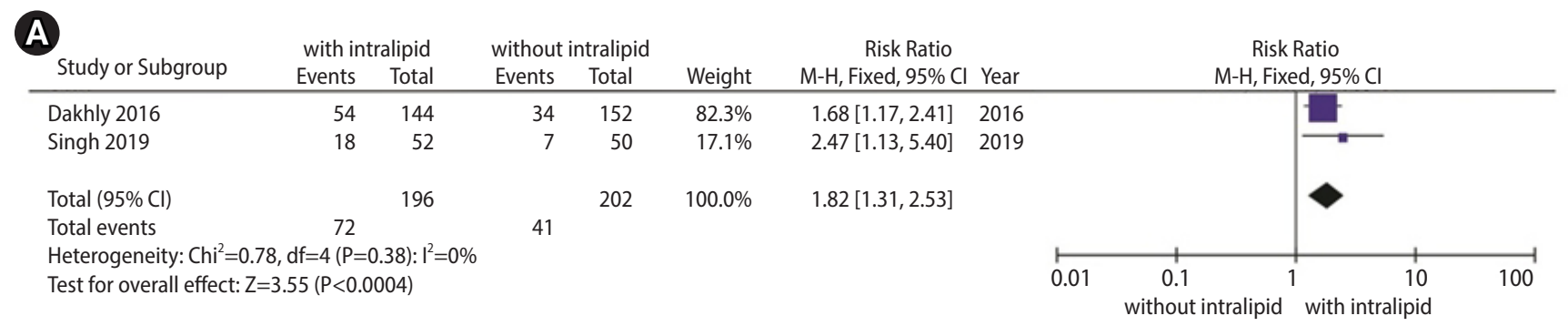

\section{B}

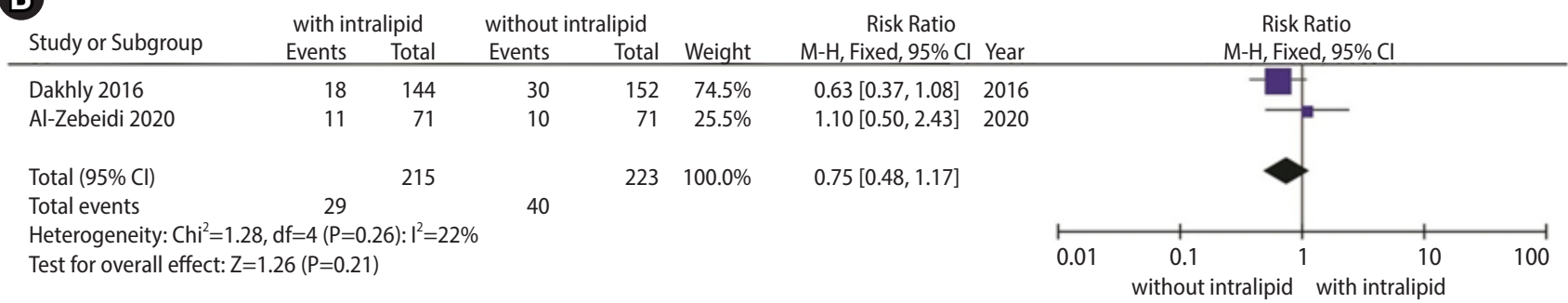

Figure 3. Meta-analysis of the ongoing pregnancy rate (A) and miscarriage rate (B). $\mathrm{M}-\mathrm{H}$, Mantel-Haenszel; $\mathrm{Cl}$, confidence interval.

ing of the data revealed no beneficial effect of intralipid injection on the miscarriage rate $(\mathrm{RR}, 0.75 ; 95 \% \mathrm{Cl}, 0.48-1.17 ; p=0.21)$. Homogeneity between the two RCTs was identified using the $l^{2}$ statistic (22\%). Thus, we selected a fixed-effect model (Figure 3B).

\section{5) Adverse events}

Four of the included studies assessed adverse events, which did not show a statistically significant difference between the intervention group and control group [12-14,18]. In two of these trials [14,18], one congenital diaphragmatic hernia and two congenital external ear anomalies were reported in the intralipid treatment groups. In the other trials [12,13], no adverse events of intralipid administration were reported.

\section{Publication bias analysis}

The five RCTs included in this meta-analysis were evenly distributed across the graph in the funnel plot analysis, showing no publication bias (Figure 4). 


\section{Subgroup analysis and sensitivity analysis}

We did not conduct a subgroup analysis since it was not possible to extract data for populations without RIF or RSA. In a subgroup analysis of women with previous implantation failure versus women with RSA, we found higher CPR and LBR for women with previous implantation failure, and the pooled RRs were $1.74(95 \% \mathrm{Cl}, 1.27-$ 2.40) and 1.98 (95\% Cl, 1.39-2.80), respectively (Supplementary Figure 3). For women with RSA, only one study was reported, according to which LBR improved compared with placebo or no treatment (Supplementary Figure 3). Sensitivity analyses using a random-effect model or limited to only published studies did not result in different conclusions regarding the $\mathrm{CPR}$, $\mathrm{LBR}$, ongoing pregnancy rate, and miscarriage rate (Supplementary Tables 1 and 2).

\section{Discussion}

This meta-analysis was conducted to evaluate the effectiveness of intralipid administration for infertile women undergoing IVF. Five RCTs involving a total of 840 infertile women were included. The meta-analysis showed that IVF outcomes, including the CPR, ongoing pregnan$c y$, and live birth, improved when intralipid was used as an adjunct treatment in women undergoing IVF, especially for RIF or RSA.

The current review showed that intralipid administration improved the LBR compared with the control group (RR, 1.85; 95\% Cl, 1.44-2.38) (Figure 2B). This finding is consistent with the preliminary results of a meta-analysis presented by Asif et al. [19] at the 34th Annual Meeting of the European Society of Human Reproduction and Embryology (RR, 2.13; 95\% Cl, 1.35-3.36). This review provided more reliable evidence because it analyzed more participants than the study of Asif et al. [19] (5 RCTs with 840 participants vs. 2 RCTs with 303 participants). Another difference relates to the inclusion criteria, as the authors [19] included only women with RIF, whereas this re-

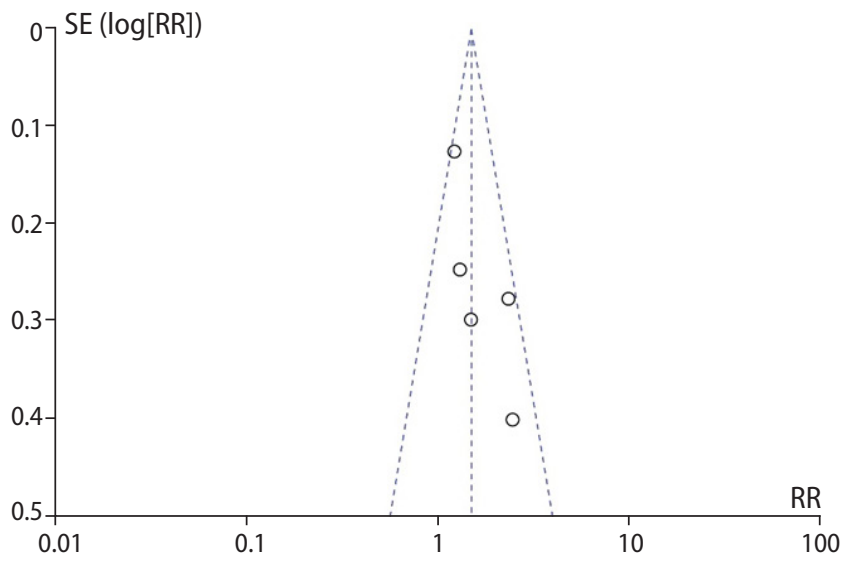

Figure 4. Funnel plot comparison showing publication bias. SE, standard error; $\mathrm{RR}$, risk ratio. view included women with RSA as well as RIF, because intralipid is known to effective in suppressing NK cytotoxicity which has been suggested as a common cause of RIF and RSA.

Although not included in this meta-analysis, we did find non-RCTs assessing the effects of intralipid on IVF outcomes. Martini et al. [16] evaluated the effects of intralipid infusion on 127 women with RIF or RSA who had elevated NK cell levels ( $\geq 19 \%$ ) and had undergone assisted reproductive technology (IVF or intrauterine insemination). They administered intralipid ( $4 \mathrm{~mL}$ of $20 \%$ intralipid diluted in 250 $\mathrm{mL}$ of normal saline) 7-10 days before embryo transfer or insemination, a second dose at a gestational age of 6 weeks and again at a gestational age of 10 weeks. In that study, intralipid failed to improve the CPR or LBR when compared with the baseline rates published by Tang et al. [20] ( $p=0.12$ and $p=0.80$, respectively). The use of historical control data was a notable limitation of this study. Another nonRCTs assessing the utility of intralipid in infertile women with RIF or RSA was reported by Check and Check [15]. They analyzed the effect of intralipid in a more specific patient group (aged 40-42 years) compared to the patient groups of the studies included in our meta-analysis. Intralipid (4 mL of $20 \%$ intralipid diluted in $100 \mathrm{~mL}$ normal saline) was infused during the mid-follicular phase. The authors demonstrated that intralipid did not increase the LBR in infertile women undergoing IVF who experienced RIF or RSA $(p=0.087)$. The differences between these findings and those of our meta-analysis may be due to the different study populations. The efficacy of intralipid in women of advanced reproductive age with RIF or RSA should be evaluated in further studies.

The immune mechanism of intralipid has not been fully identified, but several previous studies have suggested that it has immunosuppressive properties that inhibit NK cytotoxic activity and production of pro-inflammatory cytokines such as tumor necrosis factor-alpha, interleukin-6, and interleukin-8 [8,9,21]. In particular, NK cytotoxicity has been suggested as a cause of RIF and RSA $[10,11]$. It has been shown that intralipid affects NK cells through receptors such as the $G$ protein-coupled receptor and peroxisome proliferator-activated receptor (PPAR) [22-25]. The fatty acids in intralipid and its metabolites act as ligands that activate PPAR expressed in NK cells. PPAR activation reduces NK cytotoxicity and consequently enhances implantation and maintains pregnancy [26-29]. PPAR also plays an important role in implantation, invasion of cytotrophoblasts, embryo growth, and formation of the placenta $[25,30]$.

Like intralipid, IVIG is also effective in suppressing NK cytotoxicity $[29,31]$ and has been used successfully to treat RIF and RSA. However, IVIG is expensive and is associated with side effects such as transfusion-transmitted diseases because of a blood product. In recent years, some authors have suggested that intralipid and IVIG are equally effective in decreasing NK cell cytotoxicity. Coulam and Aca- 
cio [32] compared the effects of intralipid and IVIG in infertile women who had experienced reproductive failure and increased NK cell levels $(n=442)$. There were no significant differences between the intralipid group ( $n=200)$ and IVIG group $(n=242)$ in the LBR or ongoing pregnancy rate (61\% vs. $56 \%$, respectively). In 2016, Meng et al. [10] conducted an RCT to compare the effects of intralipid $(n=78)$ and IVIG $(n=78)$ in women with unexplained RSA and elevated NK cell levels (>20\%). The authors noted that the successful pregnancy rates of the two groups were similar (92.1\% vs. $88.2 \%$; $p=0.415)$. These data suggest that intralipid is sufficiently effective and may be used as an alternative to IVIG for the treatment of RSA or RIF. Furthermore, intralipid is less expensive than IVIG. However, RCTs with larger sample sizes are needed to confirm that intralipid and IVIG are both effective treatments for RIF or RSA.

To ensure quality, we included only RCTs in the meta-analysis. Furthermore, selection bias was reduced, as two reviewers independently selected the trials and extracted the data. There were also several limitations to our review. One was the heterogeneity of the included trials. There were differences among the study populations (infertile women with RIF, RSA, or a history of implantation failure). There was also variability among the intralipid administration protocols in terms of dose, frequency, and duration. Therefore, the optimal dose, frequency, and duration of intralipid were not confirmed. Another limitation is that only a small number of studies were included in the meta-analysis. Despite these limitations, the present meta-analysis provides clinicians with a meaningful summary of the existing studies on the effectiveness of intralipid for infertile women undergoing IVF with RIF or RSA.

In conclusion, the findings of the current meta-analysis and systematic review suggest that intralipid administration may improve IVF outcomes, especially in women with RIF or RSA. However, due to some limitations of this review, intralipid in women undergoing IVF should be used with caution and these findings need to be further evaluated in larger, well-designed studies. The mechanisms and safety of intralipid and the optimal protocol for intralipid administration should also be explored in future research.

\section{Conflict of interest}

Sang Woo Lyu is an editorial board member of the journal but was not involved in the peer reviewer selection, evaluation, or decision process of this article. No other potential conflicts of interest relevant to this article were reported.

\section{ORCID}

E Jung Han

https://orcid.org/0000-0002-1913-6528
Hye Nam Lee Min Kyoung Kim Sang Woo Lyu Woo Sik Lee https://orcid.org/0000-0002-8427-4150 https://orcid.org/0000-0002-1753-2674 https://orcid.org/0000-0001-5572-0898 https://orcid.org/0000-0002-2329-1774

\section{Author contributions}

Conceptualization: SWL. Data curation: EJH, SWL. Formal analysis: EJH, SWL, WSL. Funding acquisition: SWL. Methodology: EJH. Project administration: WSL. Visualization: HNL, MKK. Writing-original draft: EJH. Writing-review \& editing: SWL.

\section{Supplementary material}

Supplementary material can be found via https://doi.org/10.5653/ cerm.2020.04266.

\section{References}

1. Zeyneloglu HB, Onalan G. Remedies for recurrent implantation failure. Semin Reprod Med 2014;32:297-305.

2. Kumar P, Mahajan S. Preimplantation and postimplantation therapy for the treatment of reproductive failure. J Hum Reprod Sci 2013;6:88-92.

3. Simon A, Laufer N. Repeated implantation failure: clinical approach. Fertil Steril 2012;97:1039-43.

4. Makrigiannakis A, Petsas G, Toth B, Relakis K, Jeschke U. Recent advances in understanding immunology of reproductive failure. J Reprod Immunol 2011;90:96-104.

5. Kwak-Kim J, Han AR, Gilman-Sachs A, Fishel S, Leong M, Shoham Z. Current trends of reproductive immunology practices in in vitro fertilization (IVF): a first world survey using IVF-Worldwide.com. Am J Reprod Immunol 2013;69:12-20.

6. Penzias AS. Recurrent IVF failure: other factors. Fertil Steril 2012; 97:1033-8.

7. Beaulieu LM, Vitseva O, Tanriverdi K, Kucukural A, Mick E, Hamburg N, et al. Platelet functional and transcriptional changes induced by intralipid infusion. Thromb Haemost 2016;115:114756.

8. Granato D, Blum S, Rossle C, Le Boucher J, Malnoe A, Dutot G. Effects of parenteral lipid emulsions with different fatty acid composition on immune cell functions in vitro. JPEN J Parenter Enteral Nutr 2000;24:113-8.

9. Mayer K, Meyer S, Reinholz-Muhly M, Maus U, Merfels M, Lohmeyer J, et al. Short-time infusion of fish oil-based lipid emulsions, approved for parenteral nutrition, reduces monocyte proinflammatory cytokine generation and adhesive interaction with endothe- 
lium in humans. J Immunol 2003;171:4837-43.

10. Meng L, Lin J, Chen L, Wang Z, Liu M, Liu Y, et al. Effectiveness and potential mechanisms of intralipid in treating unexplained recurrent spontaneous abortion. Arch Gynecol Obstet 2016;294:2939.

11. Tang AW, Alfirevic Z, Quenby S. Natural killer cells and pregnancy outcomes in women with recurrent miscarriage and infertility: a systematic review. Hum Reprod 2011;26:1971-80.

12. Al-Zebeidi J, Agdi M, Lary S, Al-Obaid S, Salim G, Al-Jaroudi D. Effect of empiric intravenous intralipid therapy on pregnancy outcome in women with unexplained recurrent implantation failure undergoing intracytoplasmic sperm injection-embryo transfer cycle: a randomized controlled trial. Gynecol Endocrinol 2020;36: $131-4$.

13. Dakhly DM, Bayoumi YA, Sharkawy M, Gad Allah SH, Hassan MA, Gouda HM, et al. Intralipid supplementation in women with recurrent spontaneous abortion and elevated levels of natural killer cells. Int J Gynaecol Obstet 2016;135:324-7.

14. Singh N, Davis AA, Kumar S, Kriplani A. The effect of administration of intravenous intralipid on pregnancy outcomes in women with implantation failure after IVF/ICSI with non-donor oocytes: a randomised controlled trial. Eur J Obstet Gynecol Reprod Biol 2019;240:45-51.

15. Check JH, Check DL. Intravenous intralipid therapy is not beneficial in having a live delivery in women aged 40-42 years with a previous history of miscarriage or failure to conceive despite embryo transfer undergoing in vitro fertilization-embryo transfer. Clin Exp Obstet Gynecol 2016;43:14-5.

16. Martini AE, Jasulaitis S, Fogg LF, Uhler ML, Hirshfeld-Cytron JE. Evaluating the utility of intralipid infusion to improve live birth rates in patients with recurrent pregnancy loss or recurrent implantation failure. J Hum Reprod Sci 2018;11:261-8.

17. El-khayat W, El Sadek M. Intralipid for repeated implantation failure (RIF): a randomized controlled trial. Fertil Steril 2015;104:E26.

18. Gamaleldin I, Gomaa MF, Shafik A, Akande V. Intralipid infusion does not improve live birth rates in women with unexplained recurrent implantation failure and may increase the risk of congenital malformations, a double-blinded randomised controlled trial. BJOG 2018;125:31-2.

19. Asif S, AIAhwany H, Chittawar PB, Nigdelis MP, Toulis KA, Goulis $D G$, et al. Immune therapies for women with history of unsuccessful implantation undergoing IVF/ICSI treatment: a Cochrane collaboration systematic review. Hum Reprod 2018;33:85.

20. Tang AW, Alfirevic Z, Turner MA, Drury JA, Small R, Quenby S. A feasibility trial of screening women with idiopathic recurrent miscarriage for high uterine natural killer cell density and randomizing to prednisolone or placebo when pregnant. Hum Reprod 2013;28:1743-52.

21. Roussev RG, Ng SC, Coulam CB. Natural killer cell functional activity suppression by intravenous immunoglobulin, intralipid and soluble human leukocyte antigen-G. Am J Reprod Immunol 2007; 57:262-9.

22. Fournier T, Therond P, Handschuh K, Tsatsaris V, Evain-Brion D. PPARgamma and early human placental development. Curr Med Chem 2008;15:3011-24.

23. Leslie DS, Dascher CC, Cembrola K, Townes MA, Hava DL, Hugendubler LC, et al. Serum lipids regulate dendritic cell CD1 expression and function. Immunology 2008;125:289-301.

24. Kostenis E. A glance at G-protein-coupled receptors for lipid mediators: a growing receptor family with remarkably diverse ligands. Pharmacol Ther 2004;102:243-57.

25. Desmarais JA, Lopes FL, Zhang H, Das SK, Murphy BD. The peroxisome proliferator-activated receptor gamma regulates trophoblast cell differentiation in mink (Mustela vison). Biol Reprod 2007;77:829-39.

26. Clark DA. Intralipid as treatment for recurrent unexplained abortion? Am J Reprod Immunol 1994;32:290-3.

27. Zhang X, Rodriguez-Galan MC, Subleski JJ, Ortaldo JR, Hodge DL, Wang JM, et al. Peroxisome proliferator-activated receptor-gamma and its ligands attenuate biologic functions of human natural killer cells. Blood 2004;104:3276-84.

28. Delerive P, Fruchart JC, Staels B. Peroxisome proliferator-activated receptors in inflammation control. J Endocrinol 2001;169:453-9.

29. Roussev RG, Acacio B, Ng SC, Coulam CB. Duration of intralipid's suppressive effect on NK cell's functional activity. Am J Reprod Immunol 2008;60:258-63.

30. Kowalewski MP, Meyer A, Hoffmann B, Aslan S, Boos A. Expression and functional implications of peroxisome proliferator-activated receptor gamma (PPARץ) in canine reproductive tissues during normal pregnancy and parturition and at antiprogestin induced abortion. Theriogenology 2011;75:877-86.

31. Kwak JY, Kwak FM, Ainbinder SW, Ruiz AM, Beer AE. Elevated peripheral blood natural killer cells are effectively downregulated by immunoglobulin $\mathrm{G}$ infusion in women with recurrent spontaneous abortions. Am J Reprod Immunol 1996;35:363-9.

32. Coulam CB, Acacio B. Does immunotherapy for treatment of reproductive failure enhance live births? Am J Reprod Immunol 2012;67:296-304. 